\title{
Recommender - Potentials and Limitations for Self-Study in Higher Education from an Educational Science Perspective
}

\author{
https://doi.org/10.3991/ijai.v2i2.14763 \\ Christina Gloerfeld $\left.{ }^{(}\right)$, Silke E. Wrede, Claudia de Witt \\ FernUniversität in Hagen, Hagen, Germany \\ Christina.Gloerfeld@FernUni-Hagen.de \\ Xia Wang \\ German Research Center for Artificial Intelligence (DFKI), Berlin, Germany
}

\begin{abstract}
Artificial intelligence is one of the disruptive technologies, that drives change in our society and economy, but also in our educational system. Educational data mining, machine learning and expert systems are increasingly being used to support study and teaching. This article takes an educational science perspective to present an approach, on how to use a recommender system for students to support inquiry-based learning and self-regulated learning. Along the course of the semester various AI-based applications like automatic assessments, interest visualizations or a learning strategy finder assist in the different phases of the semester. When planning and designing there recommender systems, the most important premise is to foster self-study of the students.
\end{abstract}

Keywords-AI in Education, recommender, educational science perspective, inquiry-based learning, self-regulated learning, self-study

\section{Introduction}

The social challenges and political demands for inclusion, lifelong learning, participation in social developments, scientific competitiveness [1], academization of the professional world, higher student numbers and degrees are putting universities under immense pressure [2]. The use of digital technologies and virtual learning scenarios such as MOOCs, Open Educational Resources and Personal Learning Environments offers solutions for these challenges and enables personalized learning opportunities for a heterogeneous target group and large numbers of students. At the same time, the amount of information and complexity of the learning environment for learners increases. A technological solution is an AI-based recommender, which functions as "information discovery tool" [3]. In general, recommender systems assist users to make smart decisions, because they might not have the experience or competence to cope with the huge amount of information or items provided (ibid.). As stated in [4] the change from digital tools to assistant systems is compelling. Thus, a solution from an educational science perspective is required, because learners need special competences to deal with these 
changes and make use of evolving learning possibilities. It is a genuine educational task to qualify and prepare students to be able to participate in society autonomously. The upcoming of AI assistants and tools which support decision making or preselect information challenge the task to bring up autonomous individuals with the skills needed.

These skills and competences for effective workers and citizens in the society of today relate to three dimensions: information, communication and ethics and social impact [5]. The first dimension covers the handling of information as a source and as a product. Access, evaluation and organization of information combined with the ability to decide independently what knowledge is necessary to achieve certain goals, how it can be acquired and finally applied is meant by handling information as a source. In addition, information can be used to create new knowledge and generate new ideas to solve problems. The second dimension is effective communication in terms of being part of a larger community. Besides, to the appropriate selection of communication channels it is of central importance to communicate critical issues and disseminate own research. It is essential that students know how to work together and interact virtually. The ethics and social impact dimension refers to social responsibility and awareness of the challenges of the new age. This includes a certain degree of personal responsibility for one's own further education and the lifelong learning process as well as the ability to decide autonomously what knowledge is necessary to achieve certain goals, how it can be acquired and finally applied. In summary, the focus here is on the learner as an active shaper of his or her own learning process, who uses metacognitive monitoring, control and regulation processes in accordance with his or her learning goals. This is covered by the concept of self-regulated learning [6, p. 43]. Equipping each individual with these 21 st century skills like this is an important task of educational institutions [5], while they need to balance between achieving and fostering the development of the individual and at the same time meeting the demands of economy, providing students with skills and competences in line with career prospects and employability.

The demands for self-regulated learning and technical solutions with recommendations seem to contradict each other at first. On the one hand, there are recommender systems that calculate a learning offer according to identified needs, levels of knowledge, demographic data of the learners, etc. and on the other hand there is the demand for self-regulated learning according to individual learning goals with free choice of methods and contents. Therefore, it has to be investigated how personalized learning recommendations can be designed with intelligent systems that simultaneously promote self-regulated learning. Inquiry-based learning is a very promising educational approach to solve these contradictions and uses AI to support learners without patronizing. The high individual performance emerging in an inquiry process is based on the self-regulating abilities of the individual, the potential of judgement and the competence of dealing with problems. These abilities can be purposefully supported by a personalized technological system because it takes into account the individual levels.

In this paper questions of how AI-based recommender systems have to be designed and deployed in order to enable and promote inquiry-based learning and to achieve selfregulated personalized learning are examined. As an example, the design of the AI.EDU Research Lab project is described and it is demonstrated how those challenges can be met. 


\section{$2 \quad$ AI and Higher Education}

$\mathrm{AI}$ is currently rapidly changing the education area at various levels. Universities need to adapt to the changes in order to stay competitive and to be able to prepare their students for new upcoming jobs [7] and gain 21st century skills [8]. For example, one hundred new AI professorships are to be created at German universities and approximately three billion euros are to be made available to boost AI expertise [9]. AI technologies are seen as the tools of the future that can be used to cope with economic, social and societal challenges [10]. Thus, it is a task of universities to prepare students with AI-based technologies, display its future relevance and include the necessary competences into their curriculum. Moreover the authors of a recent study demand to deliver abilities in AI and advanced technologies in every university department [7].

As AI is considered to be an interdisciplinary field, lots of different understandings what AI is, are in place. In [8] AI is defined "as computer systems that have been designed to interact with the world through capabilities (for example, visual perception and speech recognition) and intelligent behaviors (for example, assessing the available information and then taking the most sensible action to achieve a stated goal) that we would think of as essentially human" [p. 14]. Consequently, AI based systems require a huge amount of knowledge about the world as well as defined steps on how to process it. These can be represented in models. In general there are three models involved in an AI-based learning system: a pedagogical model (or more precisely a didactic model), a domain model and a learner model [8].

For the consideration of artificial intelligence in education, different approaches can be chosen which set different focuses. The first approach is to consider AI as a tool and to examine the use and learning outcome in various contexts. Furthermore it can be used to analyze the teaching and learning process [8]. A second approach is to look at $\mathrm{AI}$ as a research subject, as it is done in basic research. Thirdly, AI can be considered as teaching or learning content, for example through courses and study programs on AI topics, but also the teaching of competencies in the field of AI. In addition, political approaches are also considered which examine AI in education on the basis of political discussions, strategies, framework conditions or support measures. In an economically oriented approach, the investments and expenditures of enterprises, start-ups, etc. are taken into account for analysis.

The approach of this article focuses on $\mathrm{AI}$ as a tool in higher education institutions in the field of teaching and learning. AI technologies are applied in the education area to help teachers to prepare their teaching and design teaching material, and to assist students in individual learning. A lot of AI-driven applications for education have been created, which support both teaching and learning. A suggestion by [8] divides AI applications into three categories: 1) personal tutors for every learner, 2) intelligent support for collaborative learning and 3) intelligent virtual reality for learning. These applications bear the potential to offer personalized learning to a highly diverse target group and support lifelong learning. This article focusses on the first category of AI in education, personal tutors for every learner. It takes an educational science perspective, because that has often been neglected in research so far but is necessary. The overview study "Artificial Intelligence in Study and Teaching" uses AI as a research subject and 
as content and examines the professorships and courses of study on AI in Germany [10]. It reveals that engineering sciences (computer science, engineering and mechanical engineering) clearly are the dominant disciplines involved [10]. However, a broader, interdisciplinary approach to AI which also includes humanities subjects, is called for (ibid.). A review of publications on AI in education confirms this dominance of certain subject groups, although AI is considered a genuinely interdisciplinary field [11]. In a systematic review, the authors record the development of publications on AI from 2007-2018 and found that $60 \%$ of the first authors have a background in Computer Science and Stem, compared to a good 6\% who come solely from Educational Science. The perspective adopted thus remains primarily a technical one (ibid.). But an educational science perspective is a necessary addition, because it bears the expertise in designing technology-based teaching/learning scenarios and distance learning experience has been growing in the pedagogical field for decades. This is where successful approaches and insights into the design of scenarios, media and the combination of methods used to achieve specific learning goals and develop competencies are gained. Teaching and learning are very complex processes and the requirements for their design increase with the use of technology.

"Successful teaching-learning processes are therefore based on a well thought-out concept, knowledge of media design and quality assurance measure" [11, p. 84f.].

AI technologies now provide promising possibilities to optimize teaching and learning with corresponding pedagogical knowledge. This is necessary to develop the necessary 21 st century skills and to support people in a sustainable development. Holmes et al. summarize that "education is both a way to mold students to fulfill the needs of society, and a means by which students may become empowered to best fulfill their own needs" [12, p. 9].

\section{Educational Science Perspective}

The starting point for planning and designing teaching and learning processes usually lies in defining the objectives or identifying an education-related problem that needs to be solved [14]. In order to address such problems, it is necessary to consider the target group, contents, learning goals, teaching methods and the choice and design of the medium [12]. If we include the use of AI in the area of media, the findings are, that learning success is not achieved by choosing the "right" medium, but rather by involving the target group, should seriously be taken in to account (ibid.). This means that just implementing a medium or distributing it, is not sufficient enough. It is necessary that the "subjective actions of the learners are activated" (ibid., p.83). Only if the students act and gain experience on their own during a learning process they will succeed.

This involvement or force into action is the basis of the concept of inquiry-based learning which relies on the pragmatism by John Dewey (ibid.). The aim of his approach is that learner construct knowledge on their own, experience interrelations throughout research projects and reflect it critically in the context of society [15]. Huber defines that in inquiry-based learning the learner conducts a whole research-process on 
his or her own [16]. That implies the formulation of research questions and hypothesis, the selection of research methods, their application, control and presentation of the results. Moreover, the results should be of interest for the scientific community.

Wildt describes a didactic concept that aims to combine learning and research and merges a typical research cycle (outer ring) with Kolb's "learning cycle" (inner ring) [17] (see fig. 1). In Dewey's sense, experience is characterized by continuity and interaction. Every experience a person makes is to be put in relation to his previous and future experiences. Living through the experience is embedded in the interaction between the individual and his environment, i.e. the situation in which the experience is made. The subsequent identification and negotiation of topics as well as the formulation of questions and hypotheses are part of the reflection in the learning cycle with focus on identifying inconsistencies or problems. So new views of reality can be thought and conceived and in research, this is realized in the concept and research design. The implementation and evaluation of the research as well as the examination of the reality constructions in practical action "in the experiment" leads afterwards again to experience or to application and thus to immersion in practice.

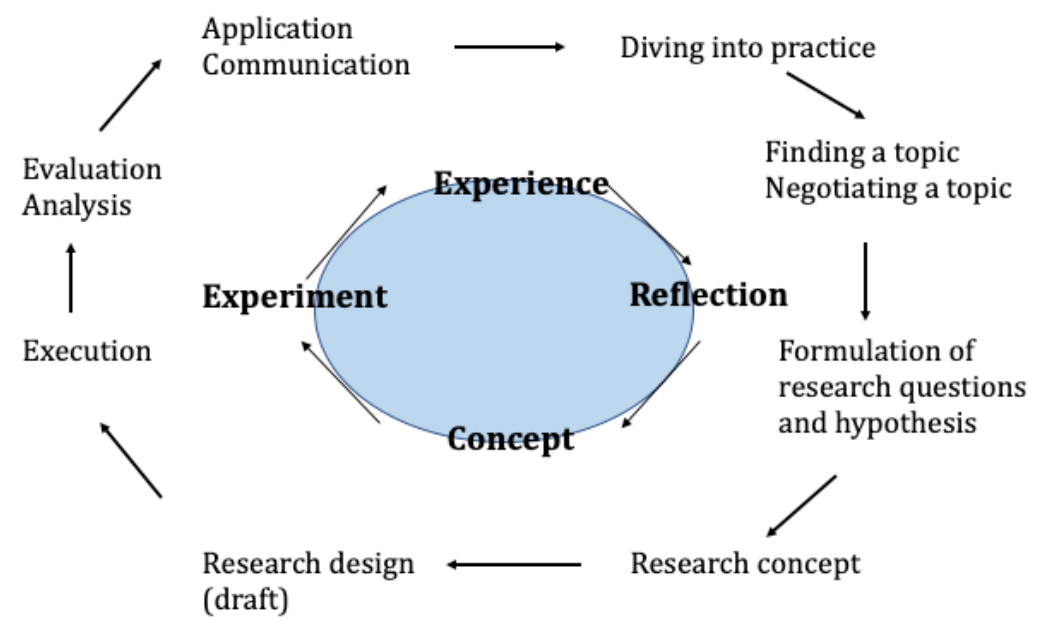

Fig. 1. Inquiry-based learning cycle for students [17]

To conduct self-driven inquiry-based learning learners need to develop sufficient strategies for learning. Learning strategies play an important role to enable self-study in a meaning of self-regulation [18]. Following [19] these can be divided into cognitive, metacognitive and resource-based learning strategies. In addition, other strategies such as motivation and emotion strategies, strategies for cooperative learning [20] or more specific strategies such as volition [21] influence learning as well.

This model of self-driven inquiry-based learning is a common approach in university teaching and AI-based applications in form of recommender are promising tools to accompany students experiencing a research process in this way. 


\section{$4 \quad$ Recommender and Self-Study}

Recommender can act as a personal tutor for every learner to support self-study and can be used to enhance inquiry-based learning. With the constant spread of digitalization of learning and the continuing growth of educational data, there has been a significant increase in the number of developing recommender systems in recent years. An analysis by [22] showed the state of recommender systems and their different features to support the learner in ways to offer further learning resources, guiding learning processes or suggesting courses to take. "Recommender systems are software tools and techniques providing suggestions for items that are most likely of interest to a particular a user." [3, p. 1] In general they provide recommendations about one specific type of item (ebd.). The goal is to support decision making for individual users, because they might be irritated or misoriented due to the information overload.

Drachsler et al. name six tasks supported by recommender systems in educational settings [22]:

- find good items

- find peers

- recommend the sequence of items

- predict learning performance

- suggest learning activities

Obviously, recommender enable personalized learning, using huge datasets to meet the needs of the learners. The systems seem to "know" better than the learner themselves what the most efficient learning approach to an individual is. But for the development of contemporary competences and skills of self-regulated individuals, learners need the freedom to take their own responsibility. It is the obligation of the educational institutions to create such free spaces, besides and within formal structures of study programs [23]. On the one hand this can be a question of loosening study regulations at the institutional level; on the other hand, it means designing teaching and learning processes with less control and predetermination of its constituents on a meso level. Recommender can be the perfect match to meet these requirements and support the different steps of inquiry-based learning. Additionally, the development of learning strategies can be supported with recommender systems to encourage self-regulated learners. The guidelines for the design imply that the learners are responsible of the learning process and choose learning goals, contents, sequence, etc. as far as possible. Following are examples of such recommender, which opens up spaces for self-directed inquiry-based learning. 


\section{Applications developed at AI.EDU Research Lab}

The FernUniversität in Hagen is an educational institution that supports lifelong learning by offering university degrees on the second chance education and basic parttime courses of study. The particular nature of the distance learning model already requires a special degree of initiative, perseverance and self-organisation. The special promotion of 21 st century skills in this context is therefore obvious.

The initial project AI.EDU Research Lab starts exactly at this point. Within an ethical and legal framework, existing data will be compiled and evaluated using AI methods; personalized recommender and support systems will be developed in order to provide students with intelligent support during their studies, to prevent dropouts and to increase their success. The focus also lies on enabling students to take responsibility for their own learning, in particular for self-regulation, and on raising awareness in dealing with algorithmized systems and automated assessments.

The recommender is fundamentally based on a combination of our knowledge-based and expert system. It consists of three components: domain model, model of the learner and didactic model (see fig. 2).

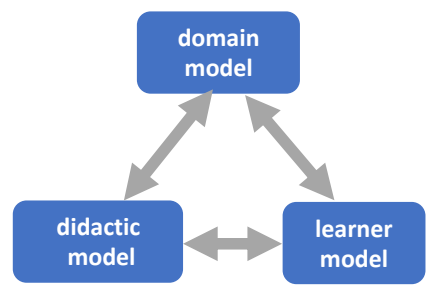

Fig. 2. Three components of the knowledge-based expert system

The domain model formally represents the structured teaching and learning material and annotated it with metadata and defines their relations and properties. The learner model stores individual information about the level of knowledge, competences and further learning data, which serve as a basis for personalized learning and the individual learning progress. Furthermore, the recommender uses a didactic model where the didactic knowledge is formalized.

The recommender system is designed for a course module in the bachelor study program in Educational Science. The goals of this module are to empower students in the areas of technical/professional, personal/social, methodological and media competence. Three consecutive semester phases structure the semester in order to enable students to develop their own research interests step by step and to achieve research results independently. First, students study the provided letters and learn the required subjectspecific contents. It is important, that the students learn to engage in discussions and self-assess their knowledge, which they need for further reflection. Referring to Wildt's didactic concept, this is the phase, in which students build on existing experiences of scientific work, deepen their knowledge and explore a subject area. In the second phase of the semester, the students prepare a term paper. At first they freely develop their own research interest and formulate possible research questions within the overall topic of 
the module. Afterwards they contact the online lectures and with their support, they finalize their research idea and the structure of their term paper. In Wildt's view, this process includes the phase of reflective experience with document research in various digital databases and the creation of hypotheses about their research objects as well as the conception of the following research contribution in form of a term paper. The interaction with the online tutor promotes the scientific discussion of the research idea and encourages reflection. In the third phase, the students write their term paper. This is what Wildt calls the execution of the experiment, whereby the students themselves can evaluate their research process. However, the assessment of performance so far is mainly based on the grading by the teacher. Figure 3 shows the structure of both processes.

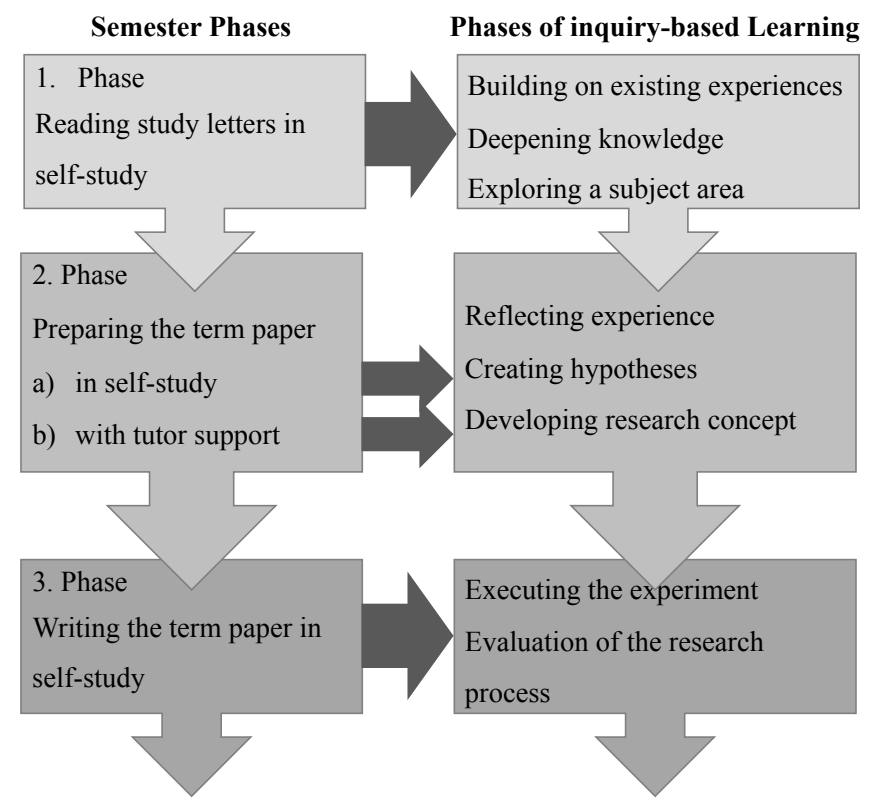

Fig. 3. Phases of the semester and the inquiry-based learning process

In the different inquiry-phases the students are supported by five applications: intelligent automatic assessment, intelligent feedback, learning strategy finder, interest visualization and organizational and structural term paper assistance. In all, these applications should offer support to the students in their individual tasks and reveal possibilities to foster and increase their competencies to become a professional and at the same time an autonomous, self-regulated learners despite and because of the recommender system. The intelligent automatic assessment analyses students' prior knowledge tests at the beginning of the module. The questions offered by the system are answered by students in free text. The system will automatically assess the students' answers by applying our machine learning model. The students then receive a system-generated personalized feedback with an option of displaying additional information on individual knowledge failure. 
During the processing of the learning material, the designed learning quizzes/exercises are used to identify the current knowledge level of the students. Based on the domain knowledge, represented in ontologies, the results of the quizzes are used by a recommender. Therefore, students receive an intelligent feedback to their exercises reflecting on what he did well or misunderstood. These recommendations refer to the processing and consolidation of individual text passages/concepts as well as cognitive learning strategies. For the latter we intend to install a learning strategy finder in addition. The aim is to promote and expand the repertoire of cognitive learning strategies. It serves to support the independent self-study of the study letters and an autonomous literature review for their research topic. If required, students receive recommendations before and during the reading process. Another application is the interest visualization. It means the opportunity to track and mark interests in the topics of the study letters and examples of examination. In addition, interests from the personal and professional background can be included. The system combines the different datasets about the students and helps them to become clear about their expertise and strengths in order to facilitate finding a matching subject for the final term paper. In the following process of writing the term paper, the students receive assistance for organizational and structural purposes. The following figure 4 shows the focus of the assignment varies in the individual phases of the semester.

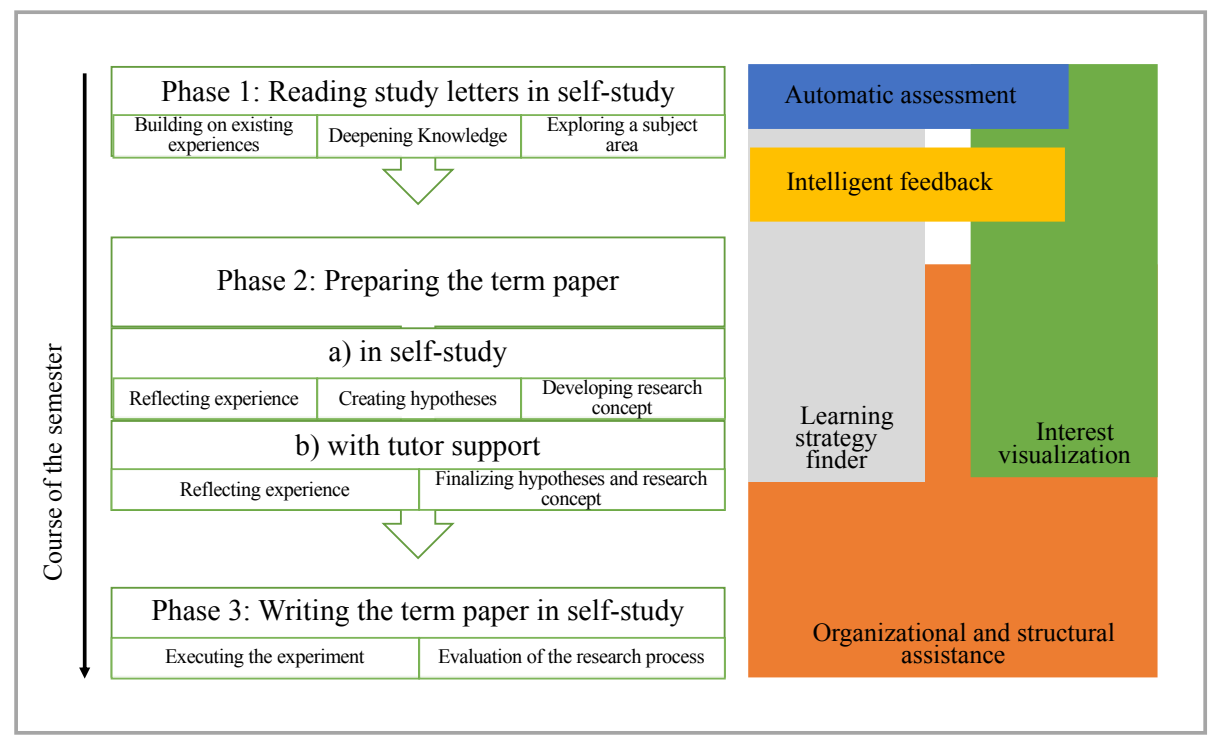

Fig. 4. Applications used in the different phases of an inquiry-based learning module

Each of the different applications helps to track user activity and increases the information about the learner and his or her learning behavior (in the learner model). Based on this, the system makes the most adequate recommendations. Thus, the recommender system has two functions in the field of "supported tasks". First, it gives recommenda- 
Paper-Recommender - Potentials and Limitations for Self-Study in Higher Education from an Edu...

tions for the development of content and its application, including both learning strategies and suggestions for learning paths. Second, it offers support in how to write a term paper by an inquiry-based learning process and gives answers to students' questions on the creation of outlines and organizational procedures. The advantage is not only that teachers are relieved of the students' recurring questions and uncertainties, but also that the students learn to independently generate solutions to problems with the help of intelligent assistance and thereby acquire their own judgment of scientific work processes. Thus, the teachers are the supporters for more in-depth or creative questions.

\section{Conclusion}

Applied AI technologies in the context of education can help students to understand how they can improve and develop competencies and how they carry out self-regulated learning. The combination of amounts of data and well-designed AI tools can help to track the way in which intelligence and learning progress develops. AI in higher education has the potential to become a personalized assistant for students without restricting their independence in academic work. Inquiry-based learning offers an approach that trains the student's ability to reflect and make judgments when developing a research question. From an educational science perspective AI applications in such didactical scenarios are especially useful to support students' competencies in self-regulated learning and to prepare them for an employability in increasingly digital professions. Of course, data law conditions must be clarified in advance, transparency created and a variety of research is still required to be able to make meaningful statements about the design, effect and suitability of re-commendations.

\section{$7 \quad$ Acknowledgement}

The AI.EDU Research Lab is funded by the D2L2 - Digitalization, Diversity, and Lifelong Learning - Consequences for Higher Education research cluster at the FernUniversität in Hagen.

\section{$8 \quad$ References}

[1] KMK, „Bildung in der digitalen Welt. Strategie der Kultusministerkonferenz“. Dez. 2016, [Online]. https://www.kmk.org/fileadmin/Dateien/pdf/PresseUndAktuelles/2017/Strategie_neu_2017_datum_1.pdf. https://doi.org/10.5771/9783828869615-5

[2] P. A. Henning, „Hochschule 4.0: Vier Missionen für die Zukunft“, in Hochschule der Zukunft: Beiträge zur zukunftsorientierten Gestaltung von Hochschulen, U. Dittler und C. Kreidl, Hrsg. Wiesbaden: Springer VS, 2018, S. 129-144. https://doi.org/10.1007/978-3$\underline{658-20403-7 \quad 8}$

[3] F. Ricci, L. Rokach, und B. Shapira, „Recommender Systems: Introduction and Challenges“, in Recommender Systems Handbook, 2. Aufl., F. Ricci, L. Rokach, und B. Shapira, Hrsg. Boston, MA: Springer US, 2015, S. 1-36. https://doi.org/10.1007/978-1-4899-7637-6 1 
Paper-Recommender - Potentials and Limitations for Self-Study in Higher Education from an Edu...

[4] R. Arnold, M. Lermen, und M. Haberer, Hrsg., Selbstlernangebote und Studienunterstützung. Baltmannsweiler: Schneider Verlag Hohengehren GmbH, 2017.

[5] K. Ananiadou und M. Claro, „21st Century Skills and Competences for New Millennium Learners in OECD Countries", OECD Education Working Papers 41, Dez. 2009. https://doi.org/10.1787/218525261154

[6] D. Leutner und C. Leopold, „Selbstreguliertes Lernen: Lehr-/Lerntheoretische Grundlagen“, in Selbstgesteuertes Lernen - Theoretische und praktische Zugänge, W. Wittwer und W. Espe, Hrsg. Bielefeld: Bertelsmann, 2003, S. 43-67.

[7] Y. Ma und K. Siau, ,Higher Education in the AI Age“, gehalten auf der Twenty-fifth Americas Conference on Information Systems, Cancun, 2019.

[8] R. Luckin, W. Holmes, M. Griffiths, und L. B. Corcier, Intelligence unleashed: an argument for AI in education. London: Pearson, 2016.

[9] Die Bundesregierung, „Strategie Künstliche Intelligenz der Bundesregierung“. Nov. 2018, [Online]. Verfügbar unter: www.ki-strategie-deutschland.de.

[10] D.-K. Mah und C. Büching, „Künstliche Intelligenz in Studium und Lehre. Überblickstudie zu Professuren und Studiengängen der künstlichen Intelligenz in Deutschland.“, VDI/VDE Innovation + Technik GmbH, Berlin, 2019. https://doi.org/10.1007/978-3-642-78545-0 12

[11] O. Zawacki-Richter, V. I. Marín, M. Bond, und F. Gouverneur, „Systematic review of research on artificial intelligence applications in higher education - where are the educators", Int J Educ Technol High Educ, Bd. 39, Nr. 2019, 2019. https://doi.org/10.1186/s41239-019$\underline{0171-0}$

[12] C. de Witt und T. Czerwionka, Mediendidaktik. Bielefeld: Bertelsmann, 2013.

[13] W. Holmes, M. Bialik, und C. Fadel, Artificial intelligence in education: promises and implications for teaching and learning. 2019.

[14] M. Kerres, Mediendidaktik: Konzeption und Entwicklung mediengestützter Lernangebote, 3. Aufl. München: Oldenbourg, 2012. https://doi.org/10.1524/9783486736038

[15] P. Bogdanow und S. Kauffeld, „Forschendes Lernen“, in Handbuch Innovative Lehre, S. Kauffeld und J. Othmer, Hrsg. Wiesbaden: Springer Fachmedien Wiesbaden, 2019, S. 143149. https://doi.org/10.1007/978-3-658-22797-5 9

[16] L. Huber, „Warum Forschendes Lernen nötig und möglich ist“, in Forschendes Lernen im Studium: aktuelle Konzepte und Erfahrungen, 2. Auflage., L. Huber, J. Hellmer, und F. Schneider, Hrsg. Bielefeld: UVW, Universitäts Verlag Webler, 2009, S. 9-35. https://doi.org/10.5771/9783845236605-59

[17] J. Wildt, „Forschendes Lernen: Lernen im ,Format“ der Forschung“, Journal Hochschuldidaktik, Bd. 20, Nr. 2, S. 4-7, 2009.

[18] F. Holz-Ebeling, Erfolg und Misserfolg beim selbstregulierten Lernen: Arbeitsprobleme im Kontext von Lernstrategien, Lernmotivation und Studienerfolg. Münster New York: Waxmann, 2017.

[19] C. Weinstein und R. Mayer, „The Teaching of Learning Strategies“, in Handbook of Research on Teaching, M. Wittrock, Hrsg. New York: Macmillan, S. 315-327.

[20] H. Mandl und H. F. Friedrich, Hrsg., Handbuch Lernstrategien. Göttingen: Hogrefe, 2006.

[21] D. Heinze, Die Bedeutung der Volition für den Studienerfolg: zu dem Einfluss volitionaler Strategien der Handlungskontrolle auf den Erfolg von Bachelorstudierenden. Wiesbaden: Springer, 2018. https://doi.org/10.1007/978-3-658-19403-1 5

[22] H. Drachsler, K. Verbert, O. C. Santos, und N. Manouselis, „Panorama of Recommender Systems to Support Learning“, in Recommender Systems Handbook, 2. Aufl., F. Ricci, L. Rokach, und B. Shapira, Hrsg. Boston, MA: Springer US, 2015, S. 421-452. https://doi.org/10.1007/978-1-4899-7637-6 12 
Paper-Recommender - Potentials and Limitations for Self-Study in Higher Education from an Edu...

[23] W. Sesink, „Statement: E-Learning und Bologna“, Zeitschrift für E-Learning, Lernkultur und Bildungstechnologie., Nr. 2, 2010.

\section{Authors}

Claudia de Witt is a professor of Education Theory and Media Education at the Institute of Educational Science and Media Research at FernUniversität in Hagen. Her focus in researching and teaching is about the influence of digitization on individuals and she has extensive experience in the conception, implementation and evaluation of e-learning and mobile seamless learning projects. She is a member of the leading team in the research focus "Digitalization, Diversity and Lifelong Learning - Consequences for Higher Education" $\left(\mathrm{D}^{2} \mathrm{~L}^{2}\right)$ of the FernUniversität in Hagen and heads the AI.EDU Research Lab together with the DFKI. She is a reviewer of various (international) journals and projects as well as international conference contributions. She has several years of experience in leading R\&D projects.

Christina Gloerfeld is a postdoctoral research assistant in the department of Educational Science and Media Education and a member of the research cluster ,Digitalization, Diversity and Lifelong Learning - Consequences for Higher Education“ $\left(\mathrm{D}^{2} \mathrm{~L}^{2}\right)$ at the FernUniversität in Hagen. Currently she is working in the AI.EDU Research Lab project in cooperation with DFKI. She has experience in the use of digital media in context-specific teaching/learning scenarios, researches the effects of digitalization in teaching/learning processes and the application of methods of artificial intelligence in higher education.

Silke E. Wrede works as a research assistant in the department of Educational Science and Media Education at the FernUniversität in Hagen since 2018. One focus of her work is the research of artificial intelligence in higher education in the project AI.EDU Research Lab, which is affiliated to the research cluster „Digitalization, Diversity and Lifelong Learning - Consequences for Higher Education" $\left(D^{2} L^{2}\right)$ of the FernUniversität in Hagen. Before that, she worked after an artistic education with pedagogical-therapeutic continuing education in various institutions and gained a wide range of teaching experience with different focus groups. The reorientation followed with the study of Educational Science at the FernUniversität in Hagen.

Xia Wang is a senior researcher at the DFKI EdTec Laboratory. She is dedicated to carrying out AI-based research with innovative applications in industry and education employing deep learning technologies and the most recent platforms for big data analytics. She currently is a member of AI.EDU Research Lab and working on building an AI learning system to provide intelligent personalized learning assistant and recommendations. Her focuses are on applying big-data-driven AI technologies to the popular online learning systems in the education area to provide intelligent learning services.

Article submitted 2020-04-10. Resubmitted 2020-05-29. Final acceptance 2020-05-30. Final version published as submitted by the authors. 